\title{
BIBLIOTECA E LEITURA EM RETRATOS: PERCEPÇÕES SOBRE O ENSINO TÉCNICO ${ }^{1}$
}

\author{
AND PORTRAIT READING: PERCEPTIONS \\ ON TECHNICAL EDUCATION
}

\author{
Joseane Amaral ${ }^{*}$ \\ Miguel Rettenmaier ${ }^{* *}$
}

\begin{abstract}
Resumo: A pesquisa "Retratos da Leitura no Brasil" é obra de referência no mapeamento da realidade leitora no país. A partir desse documento, nosso trabalho problematiza a visão acerca da leitura e o lugar da biblioteca em cursos técnicos profissionalizantes. Para tanto, relacionamos os estudos especializados de Butlen (2012a, 2012b) aos dados da quarta edição da pesquisa RLB (2016), além de observarmos percepções de um bibliotecário sobre o espaço da biblioteca em uma instituição pública de ensino. Entre os resultados, constatamos uma lacuna nos dados da RLB, o que se reflete na aparente dificuldade de promover a leitura no ensino profissionalizante, uma vez que o domínio da técnica é supervalorizado, em detrimento da leitura como agente de (trans)formação dos sujeitos.
\end{abstract}

Palavras-chave: Leitura. Biblioteca. Ensino Técnico.

Abstract: "Reading Portraits in Brazil" is a reference research that presents Brazil's reading scenery. From this document, our paper discuss the reading role and the place of the library in technical courses. To do so, we relate some Butlen's studies (2012a, 2012b) and some data from "Reading Portraits in Brazil" fourth edition (2016), as well as we discuss the librarian's perception about the library purpose in a public educational institution. The findings show us a gap in research data that reflects on promotion of reading in technical education. There is a technique overestimation to the detriment of reading practice as a means of (trans)formation of subjects.

Keywords: Reading. Library. Technical education.

\section{Leitura e formação técnica: aspectos introdutórios}

Quando abordamos questões referentes à leitura, é comum que se faça uma associação direta desta com a decodificação de signos escritos. Entretanto, ler - em uma acepção contemporânea -, envolve mecanismos que ultrapassam o nível léxico. Sobre a aprendizagem da leitura, ressaltamos as considerações do pesquisador francês Max Butlen:

\begin{abstract}
A distinção entre aprendizagem da compreensão e aprendizagem da leitura só foi feita recentemente. Foi preciso fazer balançar a crença de que a compreensão dos textos só se coloca quando o código já foi dominado, para chegar à ideia de que esse aprendizado é oportuno bem antes do aprendizado do código, ao longo desse aprendizado e, evidentemente, depois dele. (BUTLEN, 2012a, p. 7-8)
\end{abstract}

A partir dessa reflexão, reiteramos nossa assertiva introdutória: o aprendizado da leitura não está unicamente condicionado ao processamento cognitivo do código

\footnotetext{
${ }^{1}$ Artigo realizado na disciplina Seminários Especiais II, ministrada no PPGL da Universidade de Passo Fundo, com a presença do pesquisador francês Max Butlen, em 2016.

* Doutoranda em Letras, PPGL-UPF; bolsista CAPES. Mestre em Letras, Especialista em Linguística e Ensino de Línguas. Docente no IFsul campus Passo Fundo. josi.ibiruba@ gmail.com

** Professor Titular II vinculado ao PPGL-UPF. Pós-Doutor pela Universidade de Santiago de Compostela, Doutor e Mestre em Teoria da Literatura, atuando também na Linha de Pesquisa "Leitura e Formação do Leitor”. miguel@upf.br
} 
escrito; há diversas formas de ler, em diferentes etapas da vida, em ambientes e suportes cada vez mais diversificados. No presente século, a cultura digital é uma das responsáveis pelas mudanças que se processam neste âmbito. Posto que a leitura é sempre produção de significados, concordamos com a percepção do pesquisador francês - ela precede a assimilação do código escrito.

Neste artigo, nos propomos a problematizar a leitura e o espaço da biblioteca, extraindo dados da quarta edição da pesquisa Retratos da Leitura no Brasil (2016). Buscamos na pesquisa dados sobre a leitura no ensino técnico subsequente ao ensino médio. Como hipótese inicial, intuímos que é engenhosa a tarefa de incutir nesse espaço uma cultura de formação de alunos leitores, principalmente devido ao currículo dos cursos, preponderantemente voltados a disciplinas e áreas técnicas.

Outro elemento que merece ser destacado é o perfil dos estudantes matriculados nos cursos técnicos. A maioria é composta por alunos trabalhadores, cujo principal objetivo é buscar qualificação para o mercado de trabalho. Nesse sentido, perguntamos: seria profícuo lançar projetos literários envolvendo tais alunos? Nossa experiência até o presente momento demonstra certa resistência desse público em participar de tais iniciativas. Entre as principais justificativas, encontramos: "não tenho tempo para ler, pois trabalho todo o dia"; "não gosto de ler"; "prefiro fazer cursos na minha área, mais valorizados pela empresa" .

De certa forma, a escola não pode se eximir da culpa por esses resultados; o ensino da literatura frequentemente se resume ao estudo de estilos de época, fazendo com que a fruição permaneça à margem de currículos em que a categorização prepondera sobre o prazer da leitura. Coadunando com essa reflexão,

as intervenções de Max Butlen no campo educacional tocam em pontos centrais do processo de escolarização, ao abordar os desafios da formação de um leitor polivalente e da construção de uma cultura literária ao longo do ensino básico, desde a escola maternal, de modo a favorecer a constituição de uma cultura comum (BUENO; REZENDE, 2015, p. 545).

Se tal cultura não fora previamente consolidada, parece-nos árdua a tarefa de incuti-la ao longo do ensino técnico, considerando a baixa adesão de docentes de áreas técnicas a projetos de leitura. Estudantes dessa modalidade tendem a ver o curso (e, consequentemente, as leituras) como algo puramente pragmático: eu leio para aprender determinada função a desempenhar; a leitura literária, nesse contexto, ocupa um lugar periférico nas escolhas dos estudantes. Muito disso talvez se deva ao currículo do ensino técnico, predominantemente prático, e à duração dos cursos (cerca de dois anos), com ênfase em disciplinas voltadas à futura área de atuação dos sujeitos. Envolver estudantes com esse perfil em projetos literários é tarefa digna de muita persistência para o professor. Assim, concordamos que

esse desafio só poderia ser enfrentado se a formação dos professores estivesse igualmente contemplada nessa perspectiva, a qual não diz respeito apenas à formação dos professores de língua materna, visto considerar que todos os docentes acham-se envolvidos com a formação de leitores (BUENO; REZENDE, 2015, p. 545).

\footnotetext{
2 Dados obtidos informalmente pela pesquisadora, em sala de aula, em uma sondagem para possível
} realização de atividades extracurriculares de leitura. 
Apoiamos o posicionamento das autoras, uma vez que a competência de leitura perpassa todas as áreas do conhecimento; ser um leitor proficiente é essencial para a formação de todos os profissionais, uma vez que a interpretação dos signos do mundo depende do domínio da leitura. Infelizmente, não é essa a realidade constatada na maioria das escolas brasileiras: cabe aos professores de línguas - e raramente aos de pedagogia, sociologia e áreas afins -, a tarefa de empreender a cultura letrada entre os alunos.

Incomoda-nos o fato de que as lacunas não preenchidas no ensino básico dificilmente serão em disciplinas semestrais no ensino técnico. Consideramos improvável que um professor sozinho consiga suprir todas as carências de nível léxico, semântico, pragmático, transfrástico - obedecendo ao programa do curso - e ainda estimule estudantes trabalhadores a pensarem em leituras em espaços além da escola. Entretanto, muitos docentes (sem formação pedagógica) parecem "exigir" que o profissional de línguas por si só ensine o aluno a interpretar o que lê, a fazer inferências, a escrever conforme os padrões da norma culta, a identificar os gêneros concernentes à área do curso (entre outros pedidos) - em disciplinas únicas de quarenta horas ministradas em cursos técnicos. Fácil, não? Muitas vezes, os mesmos docentes que exigem tais habilidades de seus alunos se mostram relutantes ao engajamento em projetos de leitura.

Segundo Butlen (apud BUENO; REZENDE, 2015), a escola pode contribuir para que o estudante encontre novos sentidos e perspectivas, mas a instituição por si só não é suficientemente capaz de grandes reformas nas questões sociais e estruturais.

No que diz respeito à cultura letrada, os conceitos trazidos por ele [Butlen] ajudam igualmente a repensar vários aspectos, em especial a transformação das bibliotecas públicas (e escolares) em decorrência das novas práticas de leitura. A emergência e desenvolvimento paulatino de um novo modelo - Tous les livres pour tous les lecteurs [Todos os livros para todos os leitores] - ao longo do século XX promoveram o aparecimento de bibliotecas modernas, multimídias, com livre acesso, a serviço de todo tipo de leitor, as quais se multiplicaram nas últimas décadas, de modo a que a oferta pública de leitura correspondesse às evoluções das práticas sociais e culturais e às exigências populares de distração, instrução e orientações (BUENO; REZENDE, 2015, p. 547).

Apesar dessas constatações, Butlen alerta que o surgimento de bibliotecas inovadoras ${ }^{3}$, mesmo representando avanços no sistema educacional francês, não inseriu grandes remodelações no ensino de literatura nas escolas. Daí a necessidade de se repensar as metodologias que envolvem tais práticas. Que metodologias seriam promotoras da leitura, em acepção ampla, no contexto do ensino técnico? Eis um questionamento para o qual não apontamos soluções definitivas.

A Educação Profissional de Nível Técnico surgiu como resposta a uma demanda de formação de cunho prático, voltada ao mercado de trabalho. Entre os princípios norteadores explícitos na Resolução $\mathrm{n}^{\mathbf{0}}$ 6, de 20 de setembro de 2012, destacamos:

VIII - contextualização, flexibilidade e interdisciplinaridade na utilização de estratégias educacionais favoráveis à compreensão de significados e à integração entre a teoria e a vivência da prática

${ }^{3}$ No Brasil, não encontramos dados oficiais sobre a modernização de bibliotecas. 
profissional, envolvendo as múltiplas dimensões do eixo tecnológico do curso e das Diretrizes Curriculares Nacionais para a Educação Profissional Técnica de Nível Médio (BRASIL, 2012, p.2).

De acordo com o fragmento, parece implícito que as todas as áreas colaborem na formação do profissional técnico; a asserção "interdisciplinaridade na utilização de estratégias educacionais" vai ao encontro de nossa abordagem sobre projetos de leitura no ensino técnico: quando há um grupo determinado a pensar e planejar em conjunto, refletindo sobre a sua prática e propondo melhorias ao ensino, os resultados no ensino tendem a ser mais eficazes. Ainda: o documento parece esclarecer que a tarefa de "criar estratégias para compreensão de significados" não é exclusividade do núcleo de línguas, mas de todos os docentes.

Já no texto que trata do histórico da educação profissional no Brasil, constante no Parecer CNE/CEB n ${ }^{\circ}$ 16/99, destacamos a menção às (então) novas demandas da sociedade:

\begin{abstract}
A revolução tecnológica e o processo de reorganização do trabalho demandam uma completa revisão dos currículos, tanto da educação básica quanto da educação profissional, uma vez que é exigido dos trabalhadores, em doses crescentes, maior capacidade de raciocínio, autonomia intelectual, pensamento crítico, iniciativa própria e espírito empreendedor, bem como capacidade de visualização e resolução de problemas (BRASIL, 1999, p. 14).
\end{abstract}

Agora, pensemos: passaram-se quase duas décadas desde a publicação do referido Parecer; se em 1999, quando não havia um uso disseminado da internet no país, as demandas sociais pediam trabalhadores com maior "capacidade de raciocínio, autonomia intelectual, pensamento crítico", o que se pode esperar dos técnicos formados na hipermodernidade? Não seria a promoção da leitura - em sua acepção mais ampla - a via principal para o desenvolvimento de tais habilidades e competências? Com base em nossa experiência docente, ponderamos que ensino de qualidade não se faz sem pensar em formação de leitores, condição essencial para o desenvolvimento de profissionais com excelência.

\title{
2. O leitor e a biblioteca: recortes da pesquisa Retratos da Leitura no Brasil 4
}

O comportamento leitor do brasileiro vem sendo mapeado no país através da pesquisa Retratos da Leitura no Brasil (RLB), cujas edições se deram, respectivamente, nos anos 2000, 2007, 2011 e 2015. A quarta edição da pesquisa, cujos dados foram coletados entre 23 de novembro e 14 de dezembro de 2015, será um dos subsídios principais para embasar este estudo.

O objetivo central da pesquisa RLB é "conhecer o comportamento leitor medindo a intensidade, forma, limitações, motivação, representações e as condições de leitura e de acesso ao livro - impresso e digital - pela população brasileira" (INSTITUTO PRÓ-LIVRO, 2016, p. 8). Ressaltamos algumas novidades da quarta edição da pesquisa, as quais contemplam:

- Ampliação do escopo do estudo: Foram introduzidas perguntas com o objetivo de intensificar a avaliação acerca de bibliotecas (incluindo as escolares), do uso de Internet e de leituras e livros digitais. 
- Introdução do conceito de usuário de Internet: Foram introduzidas perguntas relativas ao conceito de usuário de Internet (aquele que utilizou a Internet pelo menos uma vez nos três meses anteriores à pesquisa).

- Adequação do questionário ao novo referencial internacional: Para possibilitar a comparação e construção da série histórica, alguns ajustes tiveram como referência a nova orientação do CERLALC. (INSTITUTO PRÓ-LIVRO, 2016, p. 9).

O Centro Regional para o Fomento do Livro na América Latina e Caribe (CERLALC), da Organização das Nações Unidas para a Educação, a Ciência e a Cultura (UNESCO), trabalha na criação de condições para o desenvolvimento de sociedades leitoras. Assim, com as adequações orientadas pelo CERLALC a pesquisa RLB alcança outros patamares, sendo possível estabelecer comparações em nível mais amplo.

Sobre a principal motivação para ler um livro, a RLB 4 apresenta os seguintes indicadores, como demonstrado no Gráfico 1:

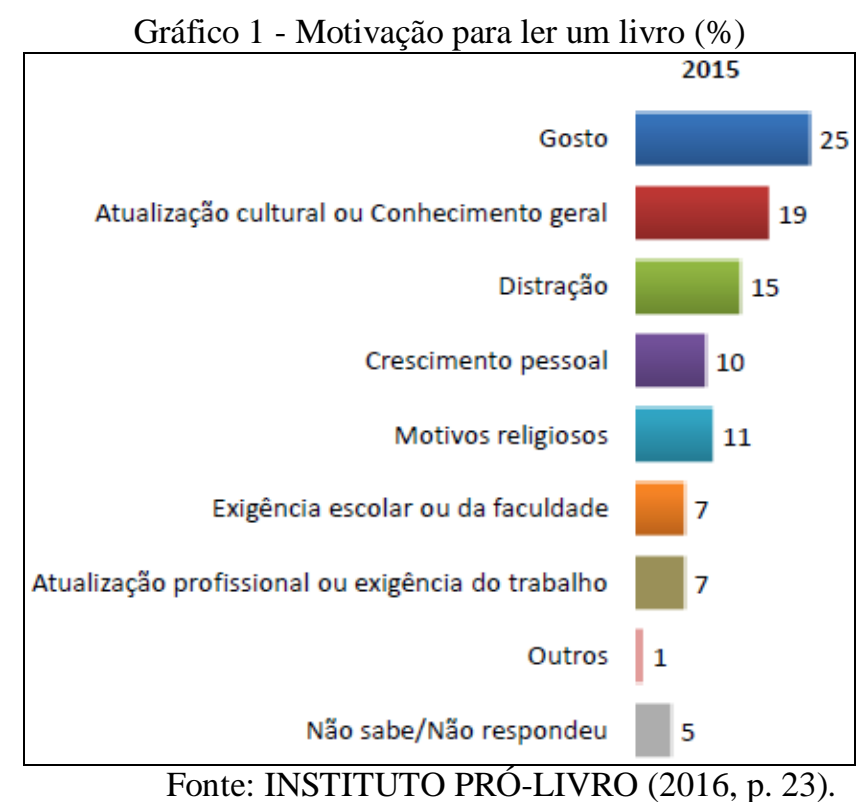

Com relação aos índices apresentados, a pesquisa ainda aponta que "quanto maior o nível de escolaridade do respondente, maiores são as menções a 'atualização cultural ou conhecimento geral' [...]e menores são as menções a [...] 'motivos religiosos"”. (INSTITUTO PRÓ-LIVRO, 2016, p. 23).

Sobre os lugares em que costumam ler livros, bibliotecas em geral são pouco consideradas, de acordo com os dados da pesquisa. Em 2015, o percentual atinge 19 pontos, enquanto a leitura em casa obtém 81\%, como pode ser observado no Gráfico 2.

Gráfico 2 - Lugares em que costuma ler livros (\%) 


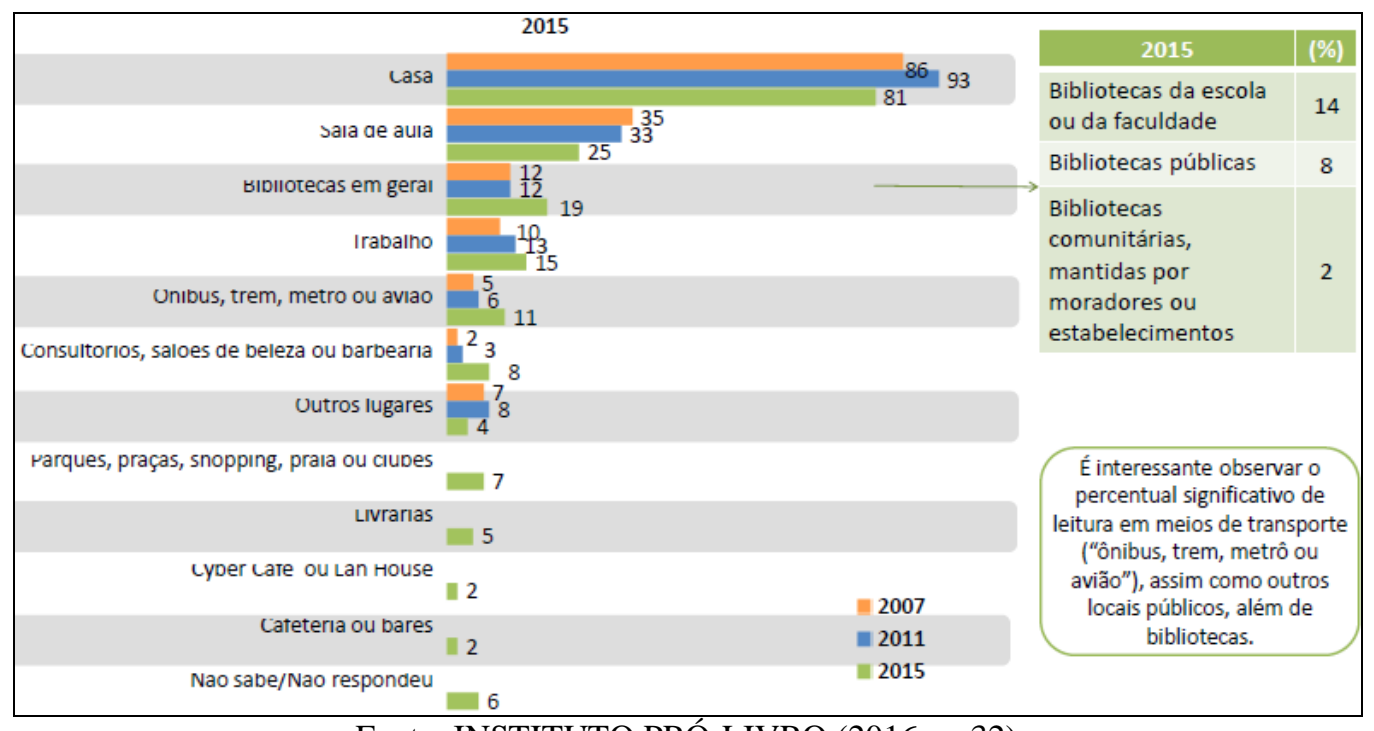

Fonte: INSTITUTO PRÓ-LIVRO (2016, p. 32).

Entretanto, no capítulo 12 - "Percepções e usos de bibliotecas" - os resultados parecem apontar uma discrepância entre representação e realidade, quando confrontamos as perguntas "lugares em que costuma ler livros" e "o que a biblioteca representa", como exposto no Gráfico 3:

Gráfico 3 - O que a biblioteca representa (\%)

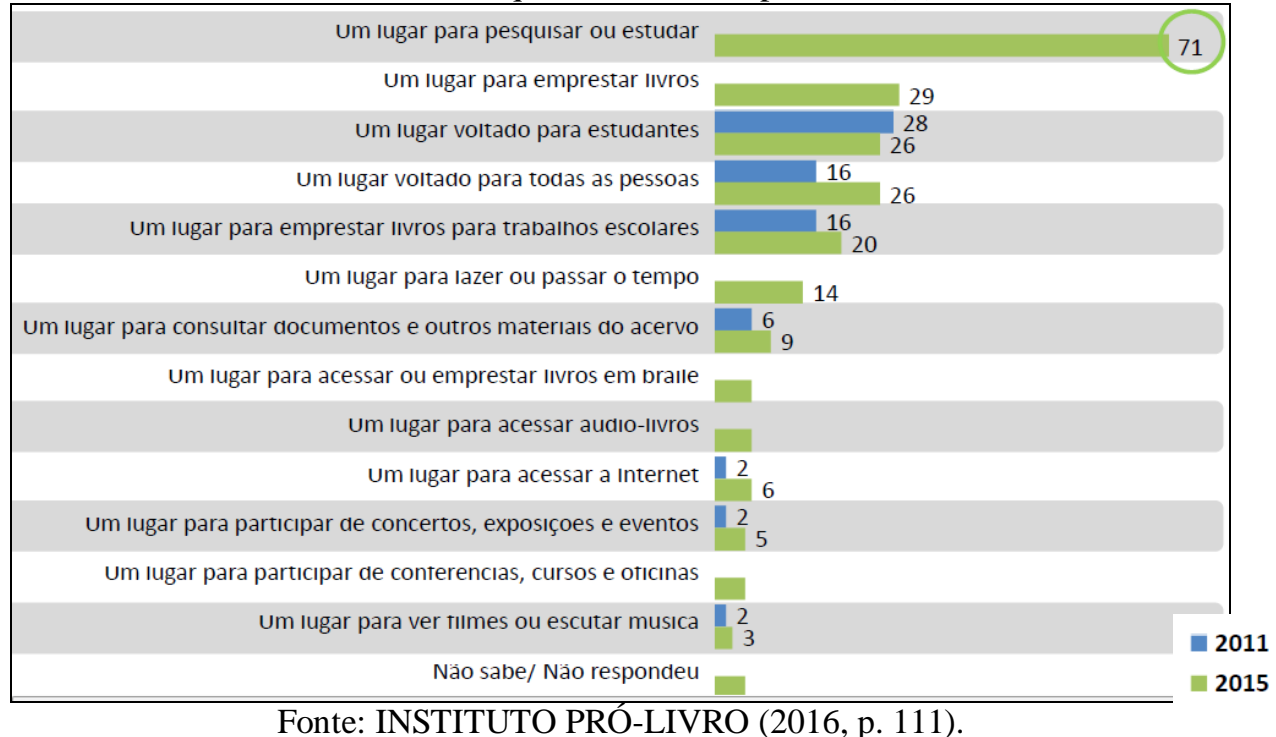

Se para $71 \%$ dos respondentes a biblioteca representa "um lugar para pesquisar ou estudar" e, ao mesmo tempo, os sujeitos indicam a casa como "o lugar em que mais costumam ler livros", a que se deve o alto percentual de alunos que apontam a casa como lugar de leitura, ao passo que a representação da biblioteca está relacionada ao estudo? Há nesses dados um interessante nicho de pesquisa: as bibliotecas (especialmente as escolares e universitárias) não estariam cumprindo com o seu papel?

Cabe esclarecer que não queremos tecer críticas às instituições ou aos bibliotecários, pois sabemos que a falta de infraestrutura e de materiais atualizados na maioria das bibliotecas brasileiras justificam certos índices da pesquisa. No Gráfico 4 podemos observar como são avaliadas as bibliotecas escolares e universitárias no país.

Gráfico 4 - Avaliação de bibliotecas escolares e universitárias (\%) 


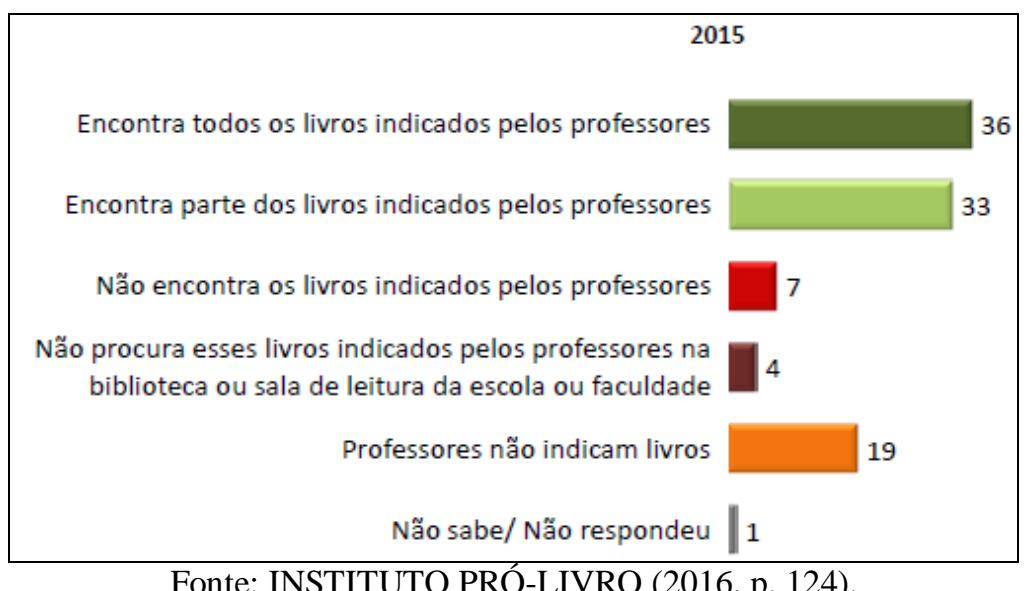

Fonte: INSTITUTO PRÓ-LIVRO (2016, p. 124).

Segundo as avaliações das bibliotecas escolares e universitárias apontadas na RLB4, em 69\% dos casos os estudantes encontram parcial ou totalmente as indicações dos professores. Tais índices - apesar de não serem os piores dessa pesquisa - reforçam o que discutimos: a escassez de materiais nas bibliotecas é um dos fatores determinantes para as lacunas no processo de formação de leitores.

Nesse sentido, de acordo com relatos do professor e pesquisador francês Max Butlen, sobre a melhoria das bibliotecas na França,

o planejamento de espaços de fácil circulação, a melhora na sinalização, a adaptação da mobília ajudaram a promover todas as práticas de leitura (leitura por lazer, de informação, leitura de pesquisa, leitura literária) para responder à diversidade de demandas (populares, escolares, acadêmicas...) sem sacrificar com isso as missões de formação cultural. (BUTLEN, 2012b, p. 34)

Ao refletirmos sobre a realidade brasileira, ainda há muito a fazer para que a biblioteca alcance o lugar que lhe é digno. Enquanto isso não ocorre, a formação de leitores deve ser pensada apesar das condições desfavoráveis que se apresentam.

Butlen, ao referir-se ao prazer primeiro da leitura, menciona a experiência da ilusão referencial, que torna o ato de ler mais próximo da realidade: "para os jogos de enunciação e identificação, o autor trabalha para fazer acreditar no que ele conta e o leitor pode sentir um 'efeito de realidade', já que ele chega a viver as aventuras, os eventos descritos, como se os vivesse pessoalmente" (BUTLEN, 2012b, p.36). O autor acrescenta ainda que as escolas e universidades têm a responsabilidade de iniciar o "prazer segundo" da leitura, não se limitando a impor textos acadêmicos e científicos, e sim deixando espaço para a emoção estética que advém da leitura literária.

\section{Pesquisa: o lugar da biblioteca no espaço técnico-acadêmico}

A pesquisa no espaço educacional é um dos meios mais eficazes para proporcionar mudanças a partir do mapeamento de realidades. Teorias são imprescindíveis para embasar todo e qualquer estudo acadêmico, mas não são suficientes para compreender a dinâmica de funcionamento do ensino, o trabalho do professor, as vivências e saberes presentes no cotidiano educacional.

Tendo em vista nosso propósito de problematizar o lugar da biblioteca no ambiente técnico-acadêmico, realizamos pesquisa em uma instituição pública de ensino de Passo Fundo - RS, que oferta cursos técnicos, cursos de graduação e pós-graduação. 
A pesquisa foi respondida por um dos profissionais bibliotecários da instituição, por meio de formulário eletrônico, e o resultado transcrito ipsis litteris, como exposto na sequência de perguntas e respostas.

1. Quantas pessoas trabalham regularmente na biblioteca de sua instituição?

05 - Cinco

2. Qual é a formação das pessoas que trabalham na biblioteca?

Duas bibliotecárias, formadas, uma auxiliar de biblioteca, formada em nível superior, uma assistente de alunos, formada em nível superior, e uma estagiária acadêmica de graduação.

3. A bibliotecária e seus/suas auxiliares procuram orientar a leitura dos alunos? É necessário auxílio? Como ele é feito?

Sim. Observamos quando o aluno demonstra não estar se localizando no acervo: perguntamos se ele precisa de ajuda. Outras vezes o aluno já chega perguntando se tem um livro sobre determinado assunto, ou de determinado autor. Efetuamos a pesquisa no catálogo online no site do campus e informamos para ele como fazer a busca. Também temos o serviço de Visita Orientada à Biblioteca no qual recebemos turmas (geralmente das disciplinas que abordam Metodologia da Pesquisa) na qual fazemos uma apresentação da biblioteca (temos um roteiro...), informando como o acervo está organizado, como pesquisar, como localizar assuntos nos livros (sumário, índice...), como consultar o catálogo online da biblioteca, renovar, reservar livros no sistema, como consultar o Portal de Periódicos da Capes.... Sobre o acervo de Literatura, apenas montamos periodicamente em uma estante expositora os livros de Literatura. Âs vezes escolhemos os livros por temática.

4. Os alunos frequentam a biblioteca mais por opção pessoal ou para realização de tarefas solicitadas pelos docentes?

Acredito que pelos dois motivos, pois temos alunos que usam bastante a biblioteca para estudar, consultar livros, fazer listas de cálculos, fazer trabalhos em grupo, se preparar para provas. Há alunos que vão retirar livros de Literatura, alguns que sentam e fazem leitura de ficção, usam seus computadores pessoais, conversam com colegas, esperam chegar a hora do ônibus ou carona para ir embora. Acredito que uma pesquisa com os alunos nos apontaria números mais precisos sobre a motivação de ida dos mesmos à biblioteca.

5. A biblioteca oferece um ambiente adequado para leitura e estudos?

No momento, já se configura insatisfatória. Organizamos da melhor maneira para acolhê-los. Mas sabemos que precisamos (e já há projeto...) de um espaço maior, onde se tenha salas de estudos em grupo, com acústica adequada para interação sem atrapalhar os demais grupos, espaço com mesas individuais para quem quer fazer a leitura silenciosa, espaço mais confortável e descontraído com poltronas, e talvez pufs... maior espaço com computadores. Serviços de cópia e impressão para os estudantes.

6. Há algum projeto de leitura envolvendo a biblioteca? Se sim, qual é o público a que se destina e quais são as maiores dificuldades na sua execução.

Não há nenhum projeto de leitura literária. Temos ideia de fazer, porém já vivenciamos situações que nos desencorajam (como por exemplo, em reunião ou momentos de apresentar a biblioteca para novos alunos, ao mencionar que temos um acervo de 
Literatura e ouvir de professores de áreas técnicas que os alunos precisam se concentrar nas áreas técnicas porque são as mais difíceis. Parece-me que incentivar a leitura literária estaria atrapalhando os estudos dos alunos... tenho essa impressão.

7. Há uma estatística de quantos livros são retirados mensalmente na biblioteca, por alunos de ensino técnico? Se sim, qual é a média mensal de leitura deste público?

Temos um sistema de gerenciamento de acervo que nos permite tirar relatórios. No entanto, precisaria de mais tempo para lhe fornecer dados neste sentido. Mas pela prática de atendimento, posso dizer que a maior parte do acervo que é emprestado é de livros técnicos e didáticos. Mas temos sim, alguns leitores de literatura.

8. Em relação aos livros buscados pelos estudantes, que tipo de leitura prevalece?

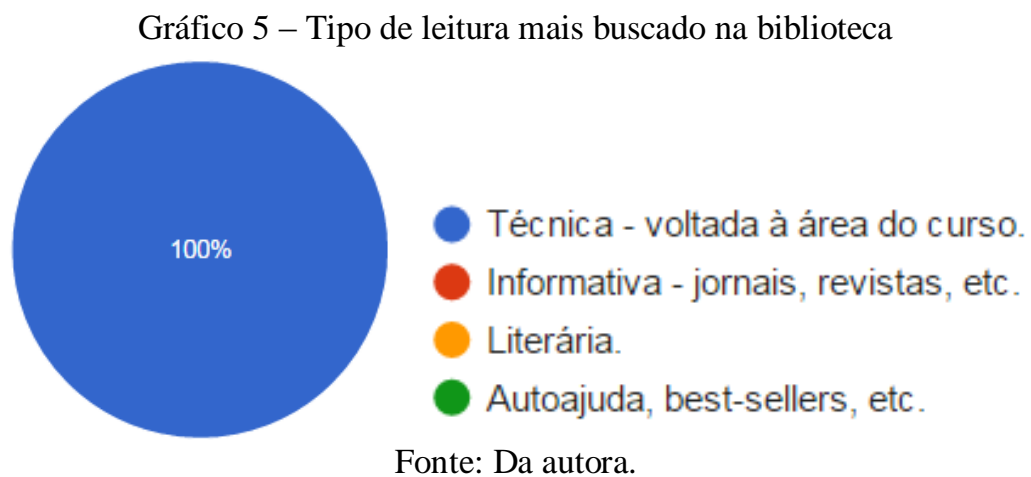

9. O que você considera essencial na construção de uma boa relação do aluno com a biblioteca? Há como tornar natural a presença do estudante neste ambiente, ou seja, algo inerente ao seu papel de educando?

Considero importante ter uma estrutura adequada, profissionais capacitados e cientes do seu papel e uma cultura institucional, isto é, gestores, professores, servidores que conheçam e considerem o potencial desse espaço e do profissional bibliotecário junto às atividades de ensino. Acredito que, no momento, estamos caminhando neste sentido. Com certeza, para vários alunos, já é natural estar, transitar e ocupar a biblioteca e seus serviços.

10. Além da presença dos computadores, há um acervo virtual da instituição disponível aos estudantes?

Sim, temos disponível o Portal de Periódicos da Capes (uma grande biblioteca virtual científica), a biblioteca virtual Domínio Público (disponibiliza livros de Literatura principalmente); a biblioteca virtual da Pearson, que disponibiliza acesso a livros virtuais para leitura no catálogo da biblioteca; além disso, é possível consultar e saber da existência e localização dos livros impressos do nosso acervo na página do campus. 


\section{Considerações Finais}

As mudanças que ocorrem na sociedade contemporânea, com a ampla invenção de novos dispositivos e suportes tecnológicos de leitura e escrita, ainda não se equivalem em termos de melhoria no campo da formação de leitores. Há mais suportes e menos proficiência de leitura; há novos dispositivos de comunicação e menos qualidade de escrita. Nesse sentido, é fastidiosa a tarefa de aprimorar o processo de formação de leitores, ofício que envolve a manutenção de políticas públicas sólidas na educação básica, da valorização dos profissionais da educação, além de inúmeros outros aspectos.

No presente estudo, cuja proposta envolveu a problematização da leitura e do espaço da biblioteca, chama-nos a atenção a ausência de menção ao ensino técnico subsequente na pesquisa RLB. Estaria esta modalidade sendo desconsiderada nos retratos do Brasil leitor? Que critérios justificariam tal exclusão? Ler, tornar-se leitor, ter acesso a livros, conviver no espaço das bibliotecas - dentre tantos indicativos demonstrados na pesquisa -, são igualmente relevantes para estudantes de cursos técnicos. Tal perspectiva leva-nos a crer que a pedagogia tecnicista parece encobrir a realidade nos cursos de formação profissional. No entanto, sem o domínio da leitura e o desenvolvimento de habilidades adjacentes é improvável formar profissionais com o perfil constante nas Diretrizes Básicas da Educação Profissional.

A biblioteca no espaço técnico-acadêmico ainda ocupa um lugar periférico, como constatado na pesquisa realizada em uma instituição pública de ensino. A aparente invisibilidade da leitura literária na modalidade profissionalizante só faz reforçar o ciclo de trabalho baseado no capitalismo. Como estimular o pensamento, se a leitura como fruição não tem lugar nos currículos, nos projetos extracurriculares e em muitas práticas docentes? Somente com a instituição de uma cultura escolar e acadêmica de promoção da leitura seremos capazes de formar sujeitos críticos, empreendedores e reflexivos, com autonomia para atuar como cidadãos na transformação da sociedade hipermoderna.

\section{Referências}

BRASIL. Parecer CNE/CEB $\mathrm{n}^{\circ}$ 16/99. Diretrizes Curriculares Nacionais para a Educação Profissional de Nível Técnico. Disponível em: <http://portal.mec.gov.br/cne/arquivos/pdf/1999/pceb016_99.pdf >. Acesso em: 30 set. 2016.

BRASIL. Ministério da Educação. Resolução no 6, de 20 de setembro de 2012. Disponível em: <http://portal.mec.gov.br/index.php?option=com_docman\&view=download\&alias=116 63-rceb006-12-pdf\&category_slug=setembro-2012-pdf\&Itemid=30192>. Acesso em: 16 out. 2016.

BUENO, B. O.; REZENDE, N. L. de. Formador de leitores, formador de professores: a trajetória de Max Butlen. Educ. Pesqui., São Paulo, v. 41, n. 2, p. 543-564, jun. 2015.

Disponível em <http://www.scielo.br/scielo.php?script=sci_arttext\&pid=S1517$97022015000200543 \& \operatorname{lng}=$ pt\&nrm=iso>. Acesso em 23 out. 2016. 
BUTLEN, M. Compreensão e interpretação literárias: duplo risco da escola ao liceu. Leitura: Teoria e Prática, Campinas, n. 58, jan./jun. 2012a.

BUTLEN, M. Para novas cooperações entre escolas e bibliotecas: retorno aos objetivos e missões. Revista Eletrônica da Faculdade de Ciências e Tecnologia do Departamento de Educação, Presidente Prudente, 2012b. Disponível em: <http://revista.fct.unesp.br/index.php/Nuances/article/viewFile/1620/1556>. Acesso em: 18 out. 2016.

INSTITUTO PRÓ-LIVRO. Retratos da Leitura no Brasil - $4^{a}$ edição. Disponível em: $<$ http://prolivro.org.br/home/images/2016/Pesquisa_Retratos_da_Leitura_no_Brasil__2015.pdf>. Acesso em: 20 out. 2016.

\section{Obras Consultadas}

BRASIL. Ministério da Educação e do Desporto. Secretaria de Educação Fundamental. Projeto Pró-Leitura na formação do professor. Brasília, DF: MEC/SEF, 1996.

Recebido em 31 de maio de 2018

Aceito em 21 de julho de 2018 